\title{
Space Charge Distribution and Nonlinear Conduction of Epoxy Nanocomposites
}

\author{
Yong-sen Han, ${ }^{1,2}$ Sheng-tao $\mathrm{Li}^{1{ }^{1 *}}$ and Dao-min $\mathrm{Min}^{1}$ \\ ${ }^{1}$ State Key Laboratory of Electrical Insulation and Power Equipment, \\ Xi'an Jiaotong University, Xi' an, Shaanxi 710049, China \\ ${ }^{2}$ Key Laboratory of Engineering Dielectrics and Its Application, Ministry of Education, \\ Harbin University of Science and Technology, Harbin, Heilongjiang 150080, China
}

(Received December 5, 2016; accepted May 11, 2017)

Keywords: epoxy resin, nanocomposite, space charge distribution, nonlinear conduction, PEA

Space charge suppression is advantageous to the development of polymeric insulation and electrical equipment, and can be achieved by introducing deep traps into the polymeric insulation or by improving the conduction. In this study, we investigated the relationship between the space charge distribution and the nonlinear conduction. Five types of epoxy-resin-based nanocomposites were prepared by the introduction of $\mathrm{SiC}$ and $\mathrm{Al}_{2} \mathrm{O}_{3}$ nanoparticles. The pulsed electroacoustic (PEA) and DC conduction measurements were used to measure the space charge distribution and DC conductivity, respectively. The space charge distributions of pure epoxy, epoxy/ $\mathrm{Al}_{2} \mathrm{O}_{3}$ nanocomposites, and $1 \mathrm{wt} \%$ epoxy/SiC nanocomposite reveal that homocharges are injected from the cathode, whereas that of $10 \mathrm{wt} \%$ epoxy/SiC nanocomposite scarcely reveals space charges. The DC current densities of these nanocomposites are different from each other and are attributed to the effect of the interaction zone around nanoparticles. Moreover, the $10 \mathrm{wt} \%$ epoxy/SiC nanocomposite shows the strongest nonlinear conduction property, whereas the epoxy/ $\mathrm{Al}_{2} \mathrm{O}_{3}$ nanocomposites hardly show it. The discrepancy in the space charge distribution of pure epoxy and epoxy nanocomposites is discussed on the basis of the variations in conduction and nonlinearity exponent. The analysis indicates that the nonlinearity exponent plays an important role in the space charge distribution.

\section{Introduction}

Space charge accumulation in polymeric insulation can distort the electric field distribution to overstress the surrounding insulation, accelerating the degradation and aging of the polymeric insulation. $^{(1,2)}$ The space charge accumulation poses a potential threat to the integrity of the polymeric insulation under electric stress. Therefore, the space charge mechanism and suppression have attracted significant attention.

Since nanocomposites were proposed by Lewis in 1994, ${ }^{(3)}$ they have been proven to improve the electrical properties of insulation materials, especially the space charge suppression. The space charge formation in the low-density polyethylene (LDPE)/MgO nanocomposite was effectively suppressed compared with that in pure LDPE. The deep traps introduced by the nanoparticles in the polymeric insulation contribute to the space charge suppression. ${ }^{(4)}$ In comparison, the space "Corresponding author: e-mail: sli@mail.xjtu.edu.cn http://dx.doi.org/10.18494/SAM.2017.1540 
charge accumulation can also be inhibited by the high electrical conduction, for example, the combination of micro-and nano-fillers in epoxy composites increases the conduction current and leads to a smaller amount of space charge than that of pure epoxy resin. ${ }^{(5)}$

The prolonged increase in conduction current may suppress the space charge accumulation, but sacrifices the electrical insulating properties of the polymeric insulation. One of the solutions to this contradiction is to introduce a nonlinear characteristic into the conduction of the polymeric insulation, namely, slightly increasing the conductivity at a high electric field to dissipate the space charge accumulation and presenting a very low conductivity at a low electric field. Such materials are called nonlinear resistive field grading composites, which can be achieved by introducing the appropriate amount of semiconducting fillers, such as silicon carbide $(\mathrm{SiC})$ and zinc oxide $(\mathrm{ZnO})$, into the polymeric matrix, such as LDPE, rubber, and epoxy resin. ${ }^{(6)}$ The nonlinear conductivity in $\mathrm{ZnO}$-filled polyester dissipates the space charge accumulation and inhibits the growth of the electrical tree, resulting in extended lifetimes. ${ }^{(7)}$

Many investigations are focused on the conductivity mechanism of nonlinear resistive field grading composites, but very little work on the process of space charge suppression has been performed. Epoxy resin as a typical insulating material is widely used in high-voltage electrical power applications and was selected as the polymeric matrix in this study. The nanoparticles of $\mathrm{SiC}$ as a typical semiconductor and $\mathrm{Al}_{2} \mathrm{O}_{3}$ as a good insulator were selected as the nanofillers. Pure epoxy and 1 and $10 \mathrm{wt} \%$ epoxy nanocomposites were investigated using space charge and DC conduction measurements. The results were compared with those obtained from the unfilled epoxy resin.

\section{Sample Preparation and Experiment Details}

The pure epoxy resin was prepared from a mixture of the bisphenol-A epoxy resin E-51, the hardener MeTHPA, and the accelerator DMP-30. This was used as the base polymer material. The nanofillers used in this study are commercially available $\mathrm{SiC}$ and $\mathrm{Al}_{2} \mathrm{O}_{3}$ nanofillers. The average particle size of the $\mathrm{SiC}$ nanoparticles is $40 \mathrm{~nm}$, whereas that of the $\mathrm{Al}_{2} \mathrm{O}_{3}$ nanoparticles is $20 \mathrm{~nm}$. The nanoparticle surface was treated by using a silane coupling agent (KH550) for preparing the epoxy nanocomposites. The filler loadings of epoxy nanocomposites were 1 and $10 \mathrm{wt} \%$.

The preparation of epoxy nanocomposites followed the standard steps, namely, mixing, degassing, and casting. The nanofiller was dispersed into the epoxy resin matrix at $50{ }^{\circ} \mathrm{C}$ and premixed for $20 \mathrm{~min}$ before other components of the mixture were added. Vacuum degassing was carried out for $20 \mathrm{~min}$. The nanocomposites were cured at $80{ }^{\circ} \mathrm{C}$ for $4 \mathrm{~h}$, and then post cured at $120^{\circ} \mathrm{C}$ for $8 \mathrm{~h}$. The samples have a thickness of about $0.23 \mathrm{~mm}$.

The space charge distribution was measured by the pulsed electroacoustic (PEA) method under $30 \mathrm{kV} / \mathrm{mm}$ at room temperature for $30 \mathrm{~min}$. The PEA measurement setup shown in Fig. 1 was made by Shang Hai Xiangtie Electromechanical Device Co., Ltd., China. The samples used for PEA measurement were evaporated with an Al electrode on both sides with a diameter of $25 \mathrm{~mm}$.

DC conduction was measured by a DC conduction measurement system as shown in Fig. 2 at $30{ }^{\circ} \mathrm{C}$ in a drying oven. The samples were placed in a three-electrode system and the measuring electrode was $30 \mathrm{~mm}$ in diameter. The steady-state current was measured at $30 \mathrm{~min}$ after applying a DC electric field and recorded for each electric field. The DC conductivity was then obtained according to the steady-state current and applied electric field. 


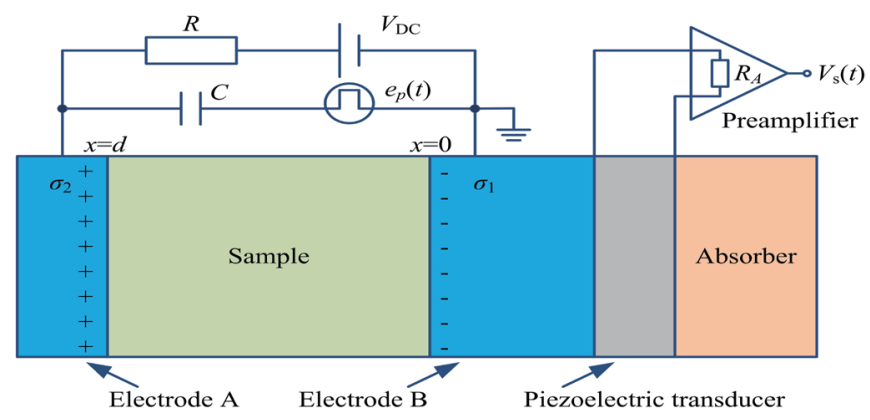

Fig. 1. (Color online) Schematic of PEA measurement setup.

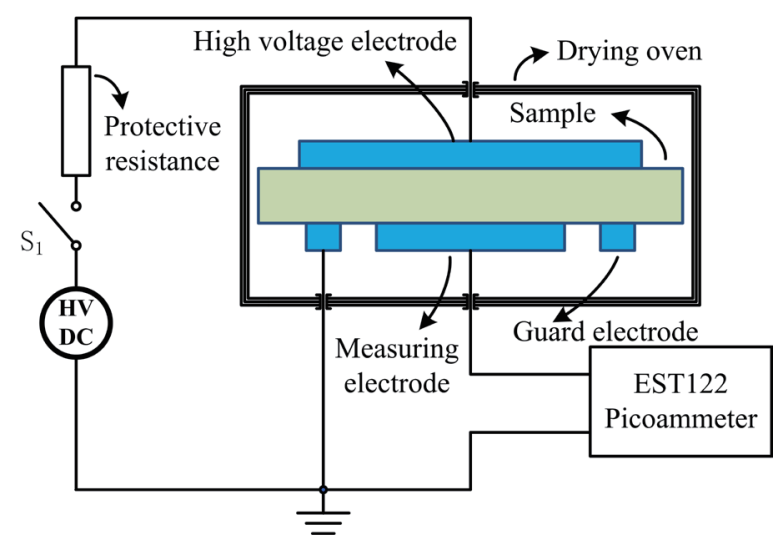

Fig. 2. (Color online) Schematic of DC conduction measurement system.

\section{Results}

\subsection{Space charge distribution}

Figure 3 shows the space charge distributions of pure epoxy and epoxy nanocomposites under 10 and $30 \mathrm{kV} / \mathrm{mm}$ after poling for $30 \mathrm{~min}$. Under $10 \mathrm{kV} / \mathrm{mm}$, all samples reveal almost no space charges, which indicates that space charges are difficult to be formed in the bulk regardless of the filler type and filler content under a low applied electric field.

However, space charges can be observed under $30 \mathrm{kV} / \mathrm{mm}$, as shown in Figs. 3(a)-3(d). These results reveal that the formulation of space charges in the sample may occur under a high applied electric field. For the pure epoxy, a small number of negative homocharges are injected from the cathode under $30 \mathrm{kV} / \mathrm{mm}$, as shown in Fig. 3(a). Similar space charge distribution can be found in Figs. 3(c) and 3(d). The difference in space charge distribution is due to the fact that the number of injected homocharges of the mentioned epoxy nanocomposites, namely, $1 \mathrm{wt} \%$ epoxy/SiC and 10 $\mathrm{wt} \%$ epoxy $/ \mathrm{Al}_{2} \mathrm{O}_{3}$ nanocomposites, is much greater than that of pure epoxy. In addition, a small number of heterocharges originating from the ionization of impurities or ionized charge transport also accumulate in the bulk, as shown in Figs. 3(b)-3(d).

In comparison, for the $10 \mathrm{wt} \%$ epoxy/SiC nanocomposite, neither homocharges nor heterocharges can be clearly observed under $30 \mathrm{kV} / \mathrm{mm}$, as shown in Fig. 3(e). Moreover, the electric field distributions under $30 \mathrm{kV} / \mathrm{mm}$ after poling for 30 min shown in Fig. 4 indicate that the electric field distribution of the $10 \mathrm{wt} \%$ epoxy/SiC nanocomposite can be nearly approximated by 


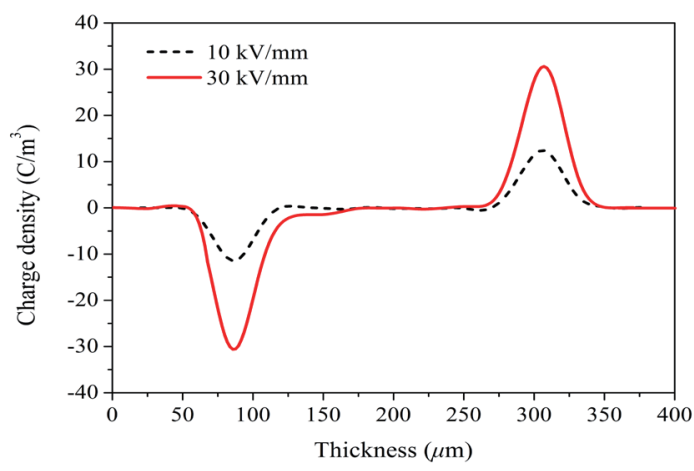

(a)

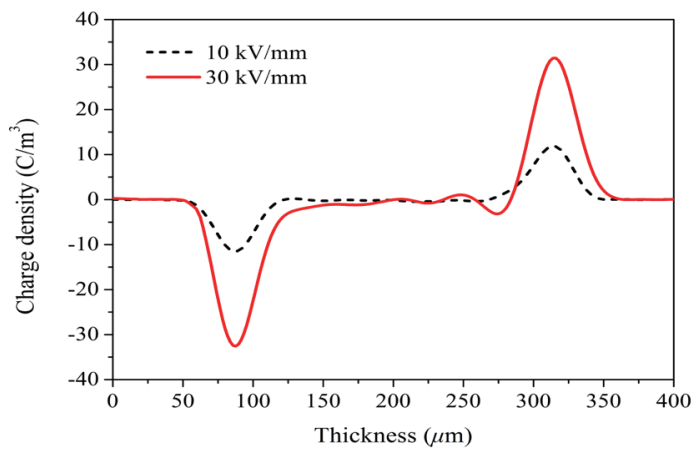

(c)

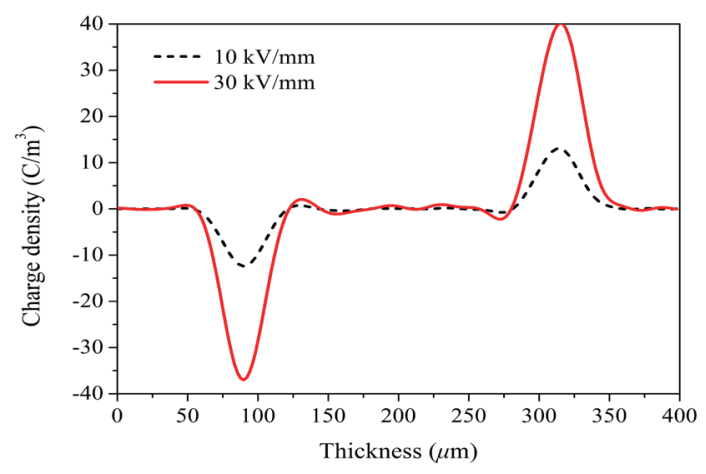

(b)

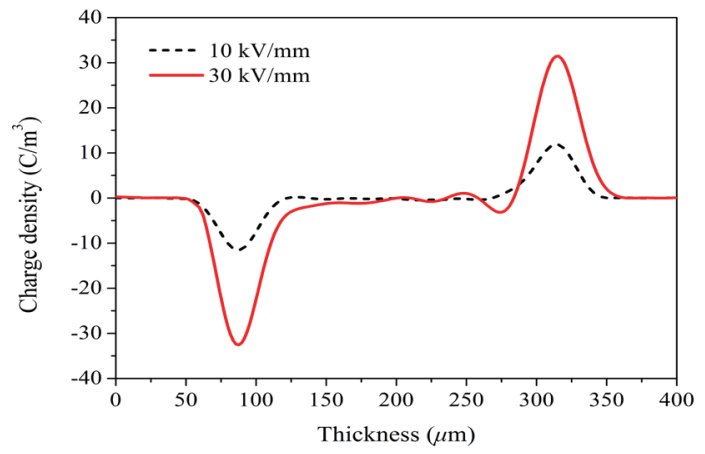

(d)

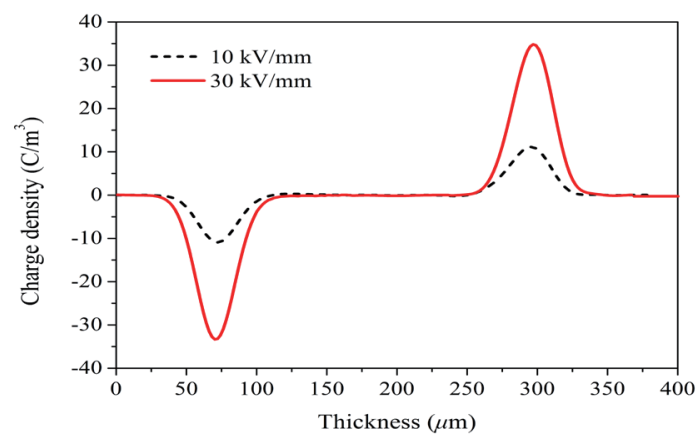

(e)

Fig. 3. (Color online) Space charge distributions of pure epoxy and epoxy nanocomposites under 10 and 30 $\mathrm{kV} / \mathrm{mm}$ after poling for $30 \mathrm{~min}$. (a) Pure epoxy, (b) $1 \mathrm{wt} \% \mathrm{Al}_{2} \mathrm{O}_{3}$ nanocomposite, (c) $1 \mathrm{wt} \% \mathrm{SiC}$ nanocomposite, (d) $10 \mathrm{wt} \% \mathrm{Al}_{2} \mathrm{O}_{3}$ nanocomposite, and (e) $10 \mathrm{wt} \% \mathrm{SiC}$ nanocomposite.

an ideal distribution, whereas those of the other samples are distorted at different levels due to the presence of space charges. These results indicate that the $10 \mathrm{wt} \%$ epoxy/ $\mathrm{SiC}$ nanocomposite has a positive effect on the space charge suppression.

To further analyze the variation in space charge in the bulk of pure epoxy and epoxy nanocomposites, the total number of charges, $Q$, in the samples is usually used and denoted as ${ }^{(8)}$

$$
Q=\int_{0}^{L}|\rho(x)| \cdot S \cdot d x,
$$




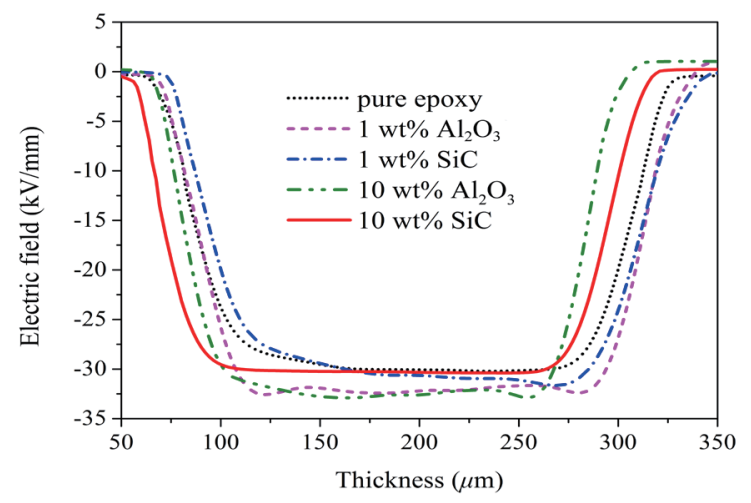

Fig. 4. (Color online) Electric field distributions of pure epoxy and epoxy nanocomposites under $30 \mathrm{kV} / \mathrm{mm}$ after poling for $30 \mathrm{~min}$.

where $\rho(x)$ is the space charge profile at the end of the polarization period and $S$ is the area of the electrodes used in the PEA measurement.

To eliminate the effect of the sample thickness, the obtained total number of charges is normalized as $Q^{\prime}=Q \times 230 / L$. Figure 5 demonstrates the normalized total number of charges for epoxy samples. The results show that the total number of charges is lower for the epoxy/SiC nanocomposites than for the epoxy $/ \mathrm{Al}_{2} \mathrm{O}_{3}$ nanocomposites, and the minimum total number of charges appears in the $10 \mathrm{wt} \%$ epoxy $/ \mathrm{SiC}$ nanocomposite among the samples. In addition, the total number of charges in the high filler loading decreases compared with that in the low filler loading regardless of nanofiller type.

\subsection{DC conduction}

The relationship between current density and applied electric field for pure epoxy and epoxy nanocomposites is shown in Fig. 6. It can be clearly seen that the current density of the $1 \mathrm{wt} \%$ $\mathrm{Al}_{2} \mathrm{O}_{3}$ /epoxy nanocomposite is lower than that of the pure epoxy. By contrast, the current densities of the other epoxy nanocomposites are higher than that of the pure epoxy. The current density is closely related to the carrier concentration and mobility, which are dependent on the interaction zone around nanoparticles, so the current density can be affected by the interaction zone.

According to the multiregion structure model, the interaction zone is composed of a bonded region and a transition region. ${ }^{(9)}$ For low filler loading, the nanoparticles can be regarded as isolated particles owing to the sufficiently large distance between neighboring nanoparticles, and the density of mobile carriers is reduced by the effect of the interaction zone, leading to the reduction in current density, as shown for the $1 \mathrm{wt} \% \mathrm{Al}_{2} \mathrm{O}_{3}$ /epoxy nanocomposite. In comparison, the semiconduction character of $\mathrm{SiC}$ nanoparticles may lead to a low carrier density, and thus the current density of the $1 \mathrm{wt} \% \mathrm{SiC} /$ epoxy nanocomposite is higher than of the pure epoxy. With increasing filler loading, the distance between neighboring nanoparticles becomes shorter and the transition region may overlap, and the carriers can get rid of the restraint from the interaction zone, increasing the mobility and density of mobile carriers. In this way, the current density would present an increasing trend, as shown for the $10 \mathrm{wt} \% \mathrm{Al}_{2} \mathrm{O}_{3} /$ epoxy nanocomposite.

Generally, the relationship between the DC conductivity and the applied electric field can be expressed as ${ }^{(10)}$ 


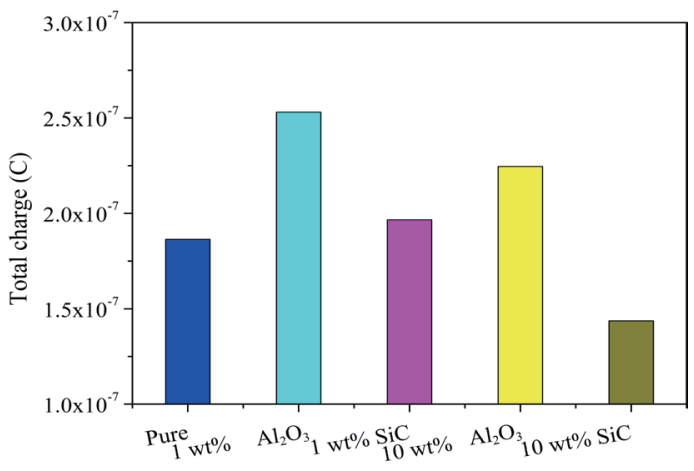

Fig. 5. (Color online) Total charge in pure epoxy and epoxy nanocomposites.

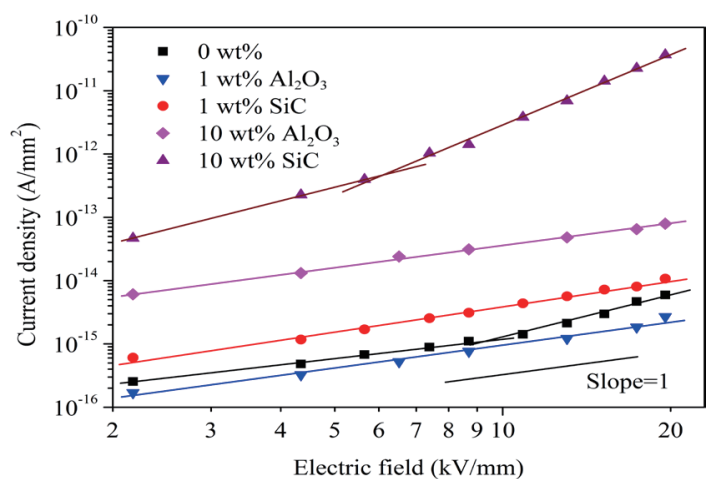

Fig. 6. (Color online) Relationship between current density and applied electric field.

$$
\gamma=\gamma_{0}\left(\frac{E}{E_{0}}\right)^{\alpha}
$$

where $\gamma$ is the conductivity, $\alpha$ is the nonlinearity exponent, $E$ is the applied electric field, $E_{0}$ is the switching electric field, and $\gamma_{0}$ is the switching conductivity.

The nonlinearity exponents of pure epoxy and epoxy nanocomposites shown in Table 1 are obtained by combining Eq. (2) with Fig. 6. Table 1 shows that the epoxy/SiC nanocomposites present a strong nonlinear conduction character, whereas both the pure epoxy and the epoxy/ $\mathrm{Al}_{2} \mathrm{O}_{3}$ nanocomposites present a weak nonlinear conduction character. Moreover, the nonlinear property of the $10 \mathrm{wt} \%$ epoxy $/ \mathrm{SiC}$ nanocomposite is stronger than that of the $1 \mathrm{wt} \%$ epoxy/ $\mathrm{SiC}$ nanocomposite. Thus, the nonlinear conduction of epoxy nanocomposites is considerably affected by the filler type as well as the filler loading. In comparison with the $\mathrm{SiC}$ particles as a typical semiconductor, the $\mathrm{Al}_{2} \mathrm{O}_{3}$ particles as a good insulator cannot provide a much higher carrier density. As a consequence, it is difficult for the epoxy $/ \mathrm{Al}_{2} \mathrm{O}_{3}$ nanocomposites to present a stronger nonlinear property. For the epoxy/SiC nanocomposites, when the filler loading is low, most of the carriers provided by $\mathrm{SiC}$ particles are restrained by the interaction zone, and the nonlinear exponent is not very high. With filler loading, the number of mobile carriers that can transport through the interaction zone increases, and then the nonlinear exponent also increases.

\section{Discussion}

It is usually considered that the space charge suppression can be attributed to the introduction of deep trapping states, which can largely capture the mobile carriers and reduce their mobility. ${ }^{(11)}$ Figure 7 shows the relationship between the total charge and the measured maximum current density of epoxy $/ \mathrm{Al}_{2} \mathrm{O}_{3}$ and epoxy/SiC nanocomposites. For epoxy nanocomposites filled with the same filler, the total charge decreases with increasing current density. It is indicated that the space charge accumulation is suppressed by the improvement in electrical conduction rather than the capture of injected charges by deep trapping states.

An interesting phenomenon that the total charge nearly decreases with increasing nonlinearity exponent can be found among all the samples except the $1 \mathrm{wt} \%$ epoxy $/ \mathrm{Al}_{2} \mathrm{O}_{3}$ nanocomposite. Figure 8 shows the relationship between the total charge and the nonlinearity exponent of the pure 
Table 1

Nonlinearity exponents of pure epoxy and epoxy nanocomposites.

\begin{tabular}{lccccc}
\hline Materials & Pure epoxy & $1 \mathrm{wt} \% \mathrm{Al}_{2} \mathrm{O}_{3}$ & $1 \mathrm{wt} \% \mathrm{SiC}$ & $10 \mathrm{wt} \% \mathrm{Al}_{2} \mathrm{O}_{3}$ & $10 \mathrm{wt} \% \mathrm{SiC}$ \\
\hline High field & 1.16 & 0.22 & 0.33 & 0.15 & $\begin{array}{l}2.67 \\
\text { Low field }\end{array}$ \\
\hline
\end{tabular}

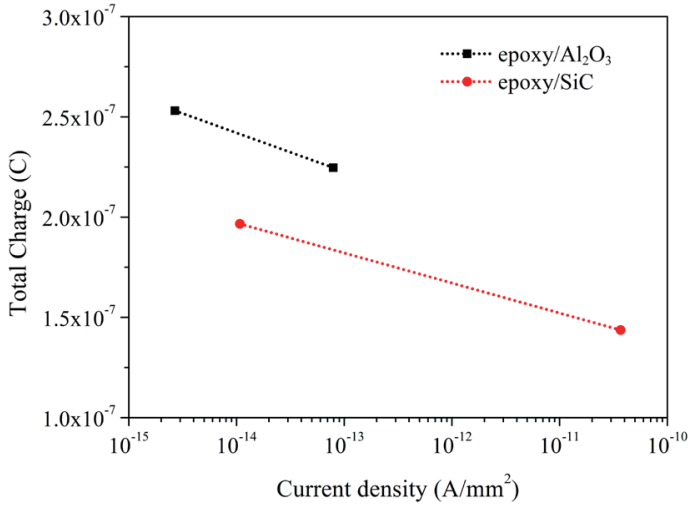

Fig. 7. (Color online) Relationship between total charge and measured maximum current density of epoxy nanocomposites.

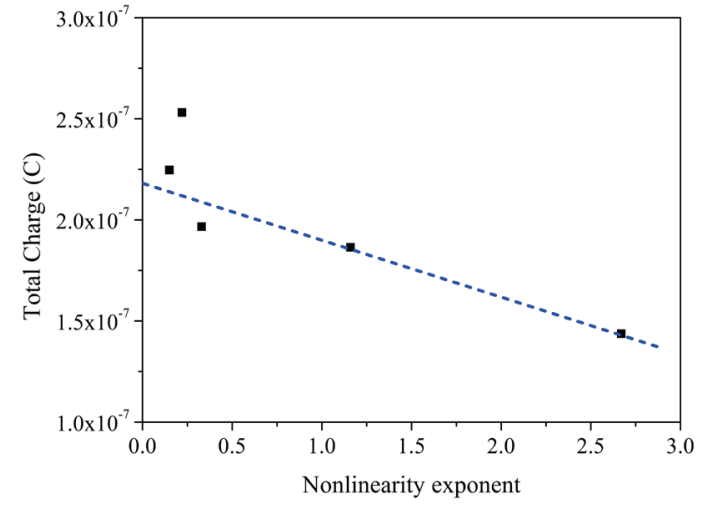

Fig. 8. (Color online) Relationship between total charge and nonlinearity exponent of pure epoxy and epoxy nanocomposites.

epoxy and epoxy nanocomposites. The charges injected from the electrodes or generated by the ionization of impurities are usually captured by traps in the polymeric insulation when they move towards the opposite electrode under the applied electric field. The trapped charges would lead to the increase in local electric field. Equation (2) suggests that a large nonlinearity exponent gives rise to a high conductivity under the same electric field and the charges trapped in the trap center can easily move out, such as in the case of the $10 \mathrm{wt} \%$ epoxy/SiC nanocomposite. By contrast, when the nonlinearity exponent is very small and even close to 0 , such as in the case of the $10 \mathrm{wt} \%$ epoxy $/ \mathrm{Al}_{2} \mathrm{O}_{3}$ nanocomposite, the conductivity can hardly increase with the electric field and the trapped charges would stay in the trap center for a long time.

The nonlinear relationship between the current density and the applied electric field can be caused by the field-dependent hopping and is described as

$$
J=A \cdot \sinh \left(\frac{\lambda q E}{2 k T}\right)
$$

where $J$ is the current density, $\lambda$ is the hopping distance, $q$ is the elementary charge, $k$ is Boltzmann's constant, and $T$ is the Kelvin temperature. Accordingly, the hopping distance as given in Table 2 is obtained on the basis of Eq. (3) with Fig. 6. The experimental data fit well with the hopping conduction mechanism owing to the large $R$-square. The hopping distances seem to be of the same order of magnitude as the available hopping distances in a report. ${ }^{(12)}$

It can be learned from Fig. 9 that the nonlinearity exponent increases, whereas the total charge almost decreases among all the samples except the $1 \mathrm{wt} \%$ epoxy $/ \mathrm{Al}_{2} \mathrm{O}_{3}$ nanocomposite when the trap state density, which is equal to $\lambda^{-3}$, decreases. Thus, it is considered that a decrease in trap 
Table 2

Hopping distances of pure epoxy and epoxy nanocomposites.

\begin{tabular}{lccccc}
\hline Materials & Pure epoxy & $1 \mathrm{wt} \% \mathrm{Al}_{2} \mathrm{O}_{3}$ & $1 \mathrm{wt} \% \mathrm{SiC}$ & $10 \mathrm{wt} \% \mathrm{Al}_{2} \mathrm{O}_{3}$ & $10 \mathrm{wt} \% \mathrm{SiC}$ \\
\hline$\lambda(\mathrm{nm})$ & 7.9 & 5.6 & 4.8 & 2.6 & 12.8 \\
$R$-square & 0.99 & 0.98 & 4.8 & 0.99 & 0.99 \\
\hline
\end{tabular}

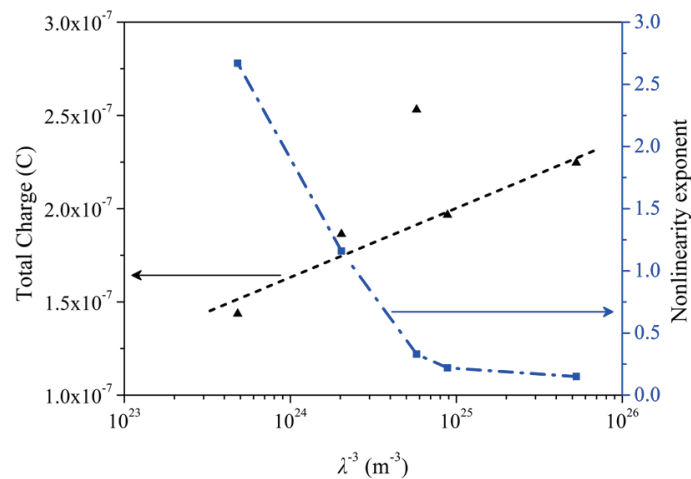

Fig. 9. (Color online) Relationships between trap state density and total charge as well as nonlinearity exponent for pure epoxy and epoxy nanocomposites.

state density leads to an increase in carrier density and/or mobility; then, the nonlinearity exponent increases and the space charge accumulation decreases.

\section{Conclusions}

Pure epoxy, epoxy/ $/ \mathrm{Al}_{2} \mathrm{O}_{3}$, and epoxy/SiC nanocomposites were prepared. The space charge distribution and DC conduction were investigated by using a PEA measurement setup and a DC conduction measurement system. The PEA measurement results showed that the epoxy/ $\mathrm{Al}_{2} \mathrm{O}_{3}$ nanocomposite tends to exhibit space charge accumulation, whereas the epoxy/SiC nanocomposite is helpful in space charge suppression. The DC conduction results showed that the nonlinear conduction of epoxy nanocomposites is considerably affected by the nanofiller type along with filler loading, and that the $10 \mathrm{wt} \%$ epoxy/SiC nanocomposite presents the strongest nonlinear conduction character among all the samples. The space charge suppression of epoxy nanocomposites may contribute to the reduction in trap state density and the resulting large nonlinearity exponent. This investigation provides for space charge suppression and nonlinear grading materials at room temperature. In the future, the dependence of the space charge and nonlinear conduction on electric field and temperature will be worth studying.

\section{Acknowledgments}

This work was supported by the National Science Foundation of China (NSFC) Grant Nos. 51337008, 11275146, 51221005, 51323012, and 51507124, and the National Basic Research Program of China Grant No. 2015CB251003. 


\section{References}

1 K. Suzuki, Y. Tanaka, T. Takada, Y. Ohki, and C. Takeya: IEEE Trans. Dielectr. Electr. Insul. 8 (2001) 78.

2 L. A. Dissado, G. Mazzanti, and G. C. Montanari: IEEE Trans. Dielectr. Electr. Insul. 4 (1997) 496.

3 T. J. Lewis: IEEE Trans. Dielectr. Electr. Insul. 1 (1994) 812.

4 T. Takada, Y. Hayase, Y. Tanaka, and T. Okamoto: IEEE Trans. Dielectr. Electr. Insul. 15 (2008) 152.

5 J. Castellon, H. N. Nguyen, S. Agnel, A. Toureille, M. Frechette, S. Savoie, A. Krivda, and L. E. Schmidt: IEEE Trans. Dielectr. Electr. Insul. 18 (2011) 651.

6 S. M. Lebedev, O. S. Gefle, and A. E. Strizhkov: IEEE Trans. Dielectr. Electr. Insul. 20 (2013) 289.

7 D. W. Auckland, W. Su, and B. R. Varlow: IEE Proc. Sci. Meas. Technol. 144 (1997) 127.

8 L. Lan, J. D. Wu, Y. Yin, X. G. Li, and Z. Li: IEEE Trans. Dielectr. Electr. Insul. 21 (2014) 1784.

9 S. T. Li, G. L. Yin, S. N. Bai, and J. Y. Li: IEEE Trans. Dielectr. Electr. Insul. 18 (2011) 1535.

10 T. Christen, L. Donzel, and F. Greuter: IEEE Electr. Insul. Mag. 27 (2011) 18.

11 S. T. Li, N. Zhao, Y. J. Nie, X. Wang, and G. Chen: IEEE Trans. Dielectr. Electr. Insul. 22 (2015) 92.

12 X. Wang, J. K. Nelson, L. S. Schadler, and H. Hillborg: IEEE Trans. Dielectr. Electr. Insul. 17 (2010) 1687.

\section{About the Authors}

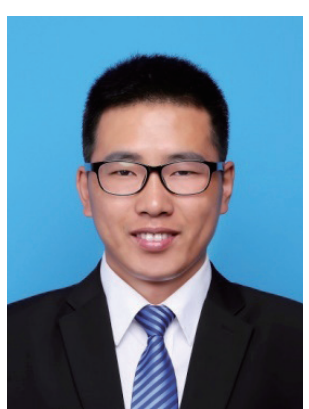

Yong-sen Han was born in Heilongjiang, China, in 1985. He received his B.Eng and M.Eng degrees in electrical engineering from Harbin University of Science and Technology, Harbin, China in 2008 and 2011, respectively. He worked as a Lecturer on high voltage and insulation technology at Harbin University of Science and Technology from 2011. Since 2013, he has been a $\mathrm{Ph} . \mathrm{D}$. candidate in electrical engineering, Xi'an Jiaotong University, Xi'an, China. His research interests include the measurement and electrical properties of nonlinear insulating dielectrics.

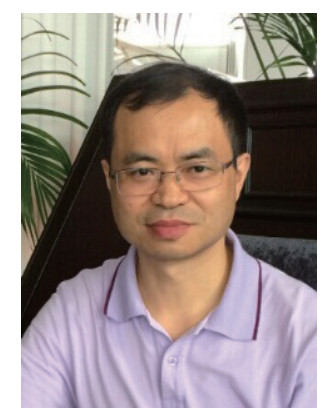

Sheng-tao Li (M'96-SM'11) received his Ph.D. degree in electrical engineering from Xi'an Jiaotong University (XJTU), China, in 1990. He was a Lecturer, Associate Professor, and Professor of XJTU in 1990, 1993, and 1998, respectively. He was a Research Fellow at Waseda University, Japan, in 1996, and was also a Senior Visiting Scholar at the University of Southampton, UK, in 2001. From 1993 to 2003, he was a deputy director of the State Key Laboratory of Electrical Insulating and Power Equipment (SKLEIPE) at XJTU. Since 2003, he has been an executive deputy director of SKLEIPE. Since 2013, he has been a deputy dean of the School of Electrical Engineering at XJTU. He was awarded as Distinguished Young Scholar of China by the National Science Foundation in 2006. He is an Associate Editor of the IEEE Transactions on Dielectrics and Electrical Insulation. His research interests include dielectrics and their applications, insulating materials, and electrical insulation. 


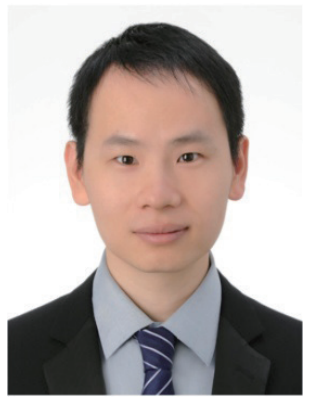

Dao-min Min received his Ph.D. degree in electrical engineering from Xi'an Jiaotong University (XJTU), China, in 2013. He was a Ph.D. visiting student in the Laboratory of Spacecraft Environment Interaction Engineering, Kyushu Institute of Technology, Japan, from 2010 to 2011 under the support of the China Scholarship Council. Since 2013, he has been a Lecturer at XJTU. From 2014 to 2015, he was a Junior Researcher at the Research Institute for Materials Science and Technology, Waseda University, Japan. His main research is charge transport and electrical breakdown properties of polymeric insulating materials. 